\title{
El cuento hispanoamericano
}

$\mathbf{E}^{\mathrm{L}}$ origen del cuento de la América Hispana hay que buscarlo en la época colonial, y casi sin excepción, se deriva en su estado inicial, de los cuentos españoles de los siglos Xvi al xvirI, pues la literatura hispanoamericana es una expresión y reflejo de la española.

Es, sin embargo, en el siglo $\mathrm{xrx}$ cuando el cuento se desarrolla y adquiere algunos caracteres propios. $\mathrm{El}$ desarrollo intelectual de nuestros países está aunado con el histórico. Dividida la América en naciones a principios del siglo XIx cada Estado dió origen a una literatura propia, con escritores de carácter típico del país. Este desarrollo independiente, sin embargo, es lento aunque certero, pues a mitad del siglo este regionalismo americano todavia no se había precisado con marcado acento. En los Andes y en México la labor intelectual adquiere mayor independencia, con tendencia autóctona. El choque de los incas y de los aztecas con el blanco, la conquista y las subsiguientes guerras, el cambio de la colonia a Estados independientes forman un conjunto de relaciones, pacíficas unas, violentas otras, que of recen al buen observador fuentes fabulosas para su arte literario.

En su principio era preciso estudiar el cuento en conjunto, sin intentos de personalidad diferencial, pues apenas se encontraban. Las fuentes literarias habían sido las mismas en México como en el Perú. México es, quizá, la primera colonia hispana en desarrollar cáracterísticas literarias propias. A medida que el desarrollo étnico, cultural y político ha ido modulando a cada distrito en forma especial, el cuento y la naración han ido tomando caracteres peculiares. Este conjunto de marcadas tendencias, sin embargo, ha creado una literatura genuinamente americana, tanto en el fondo como 
en la forma. Esa literatura ha sido original en la poesía, la historia, y en tratados de política y estudios sociales. El cuento como tal, como género literario equiparable a otros géneros, ha sido reconocido sólo en nuestros tiempos. Para ser más precisos, aparece el cuento literario en la segunda mitad del siglo xrx y ha llegado en la actualidad a un estado casi perfecto. Es el cuento donde se han registrado los rasgos literarios más sobresalientes, pues es género que se presta para mayor modalidades literarias, como son descripción de tipos, costumbres, diálogo, paisaje, etc. Una colección de cuentos de un país es el más exacto barómetro para conocer a sus habitantes. En los cuentos está retratado todo un pueblo, con todas sus contradicciones, con su profundo dolor, con su innata belleza y su magnificencia, con su energía, con su fe en el pasado y en el futuro, con su esperanza, con su odio, amor y ternura.

Se podría decir, en general, que el cuento hispanoamericano moderno data de los tiempo de Ricardo Palma, allá por 1863 cuando empezó su serie de Tradiciones peruanas. La guerra de 1898 crea una conciencia americanista entre los escritores hispanoamericanos. Hay abandono de lo castellano y aun francés, y se nota una preocupación por lo nativo, lo autóctono, la pampa, los llanos, el indio, lo propio. Se buscan la historia, la tierra, como temas centrales.

Muchos son los escritores que escriben cuentos, pero muy pocos los que se han dedicado asiduamente a este género literario. La mayor parte de los cuentistas de la América Hispana lo son de ocasión y escriben sus obras al margen de otras ocupaciones más remunerativas. No es nuestro intento presentar aquí a todos los cuentistas ni hacer un índice, sino reseñar brevemente aquellos que más sobresalen en su respectivo país. Hemos preferido estudiar este género empezando por el norte hasta llegar a la región austral del continente.

Cuba y Puerto Rico aportan en el cuento hispanoamericano temas negroides, que dan a la narración características exóticas y acción y violencia no encontradas en otras partes de América. El cuento cubano no difiere en su origen del cuento de los demás países de habla castellana. A pesar de los esfuerzos de algunos escritores cubanos de mediados del siglo XIX, tales como la Avellaneda, Ramón de Palma, Esteban Borrero Echeverría, Anselmo Suárez y Romero, y otros, el cuento en Cuba no alcanza suficiente desarrollo hasta 
después de la independencia de la isla. Después de la guerra mundial de 1914 se intensifica el cultivo del cuento en Cuba. Seguramente el más conocido de los primeros cuentistas modernos de Cuba es José Martí. En su revista La edad de oro publicó cuentos originales o traducidos, dedicados en su mayoría a los niños. Suyos son Bebé y el señor don Pomposo, y Nené travieso, tal vez los más conocidos. Martí extiende en estos cuentos su espíritu juguetón y didáctico. Jesús Castellanos fué excelente pintor de la vida rural y de La Habana. Ejerció múltiples profesiones y publicó sus cuentos en revistas y periódicos. Merecen citarse De tierra adentro, novelitas cubanas, y otra colección de cuentos: Naranjos en flor.

El cuento contemporáneo cubano está representado, sin embargo, por Alfonso Hernández Catá. Fué enemigo de Machado, lo que le inspiró un volumen de cuentos dramáticos titulado Un cementerio en las Antillas, entre los que sobresale $A l$ pagaré. Aunque cubano también está identificado con España, pues no sólo residió la mayor parte de su vida en la madre patria, sino que publicó allá casi toda su obra. Encontramos en los cuentos de Hernández Catá temas de carácter más universales, más cosmopolitas que en otros cuentistas cubanos. Su estilo y lenguaje muestran verdadera maestría en este género literario. Sus libros de ficción revelan a un psicólogo profundo, maestro de la palabra. Es el cuentista cubano de más relieve, pues cultivó este género con asiduidad y fortuna. En el cuento de Hernández Catá se nota cierta inquietud, sufrimiento, angustia. Bastaría recordar El testigo para justificar estas y otras cualidades. Entre sus libros de cuentos hay que recordar Cuentos pasionales, Sus mejores cuentos, Los frutos ácidos, Piedras preciosas, La casa de fieras, y otros.

Según autoridades competentes allá por 1925 el cuento cubano abandona sus líneas españolas y poco a poco va adquiriendo personalidad propia. Ahora los cuentistas trasladan al papel escenas cubanas del campo y de la ciudad. La ancha senda de lo nativo penetra con violencia y todo nuevo cuento aparece impregnado de costumbrismo cubano, de negroide, de lo social. Ahora el detalle o la circunstancia cubana toma vuelo. Los Relatos de Marcos Antilla de Luis Felipe Rodríguez son una colección de cuentos sobre el campesino cubano y tratan de la explotación del peón, víctima del rico hacendado. A Enrique Serpa le atraen los cuentos marítimos de su 
país. A Pablo de la Torriente Bau la vida deportiva. Carlos Montenegro tal vez sea mejor conocido fuera de Cuba. Es escritor autobiográfico y cultivador del cuento social. Reveló su talento literario durante su reclusión en la cárcel. Sus cuentos reflejan su experiencia amarga y dolorosa. Es, sin embargo, cuentista de recia personalidad, como lo ha calificado un crítico. Entre sus libros de cuentos de más mérito son Dos barcos, Los héroes, El renuevo. Conocidisimos son sus cuentos El discipulo, La ráfaga y La escopeta, entre otros. Sus cuentos de la Manigua, tan llenos de vida y colorido, forman parte de Los héroes. También merece citarse a Martín Arrilaga, que posee un estilo fuerte, manifestado en un solo volumen que se conoce: Cachumbambe, colección de cuentos escritos con arte y gracia y entre los que descuella Jugar con fuego. Luis Rodríguez-Embil, del servicio consular, ha viajado extensamente y también ha cultivado la novela y el cuento, dispersado éste en revistas y periódicos. Rubén Martínez Villena posee verdadera penetración psicológica, agudas observaciones, rasgos de intensa sensibilidad, como se observa en sus cuentos Un nombre, El automóvil, etc.

Uno de los mejores cuentistas de la isla de Puerto Rico es Cayetano Coll y Toste. Evoca el pasado imperial de España en la isla. Posee gracioso estilo. Su obra total consiste en cuentos y leyendas del pasado colonial y está contenida en Tradiciones y leyendas portorriqueñas. Coll y Toste es el Ricardo Palma de Puerto Rico. Murió en España en 1930. A. Gallardo Martell es el primer cuentista portorriqueño de las nuevas generaciones de la isla. La obra que le ha dado fama en América y España es Cuentos absurdos, publicada póstumamente (1931).

En la República de Santo Domingo el cuento también es de recientes tiempos. Juan Bosch ha publicado sus cuentos en periódicos de La Habana, Bogotá, San José de Costa Rica, Santo Domingo y otras ciudades. Le interesan el problema de la tierra, la gente del campo y las pasiones en que luchan sus personajes. Fabio Fiallo fué precursor del modernismo en Santo Domingo. Escribió poco pero fué bueno lo que publicó. Sus novelas y cuentos son comparables a otros de cualquier país. Es cuentista delicado, algo a lo francés, pero sin malicia ; discreto y lejano becqueriano. Constituyen sus temas favoritos las mujeres y el amor, como vemos en Cuentos frágiles, y Cuentos galanes. Tulio M. Cestero es escritor de ele- 
vado estilo. Es bien conocido fuera de Santo Domingo, como Fabio Fiallo. Sus dos mejores escritos son Ciudad romántica y Sangre solar.

El cuento mexicano es seguramente el más rico de la América Hispana. Es abundante, original y con características propias. Tiene orígenes más remotos que en otros países hispánicos por ser México uno de los dos virreinatos originales donde hubo más oportunidad del cultivo de las letras. En el siglo xix México cuenta con un buen número de escritores de este género literario, pero no todos conocidos como cuentistas propiamente dichos. Así pues, entre otras actividades literarias, escribieron cuentos Manuel Payno, Rodríguez Galván, Ignacio Altamirano y otros de menor nombradía. Los iniciadores del cuento en México son, sin embargo, José María Roa Bárcena y Vicente Riva Palacio. En manos de estos escritores da el cuento un avance muy notable hasta que a fines del siglo ya encontramos un género casi desarrollado por completo, cosa que no se puede decir de la novela. De Roa Bárcena son bien conocidos Lanchitas, El rey y el bufón, y Una docena de sillas para igualar. Sus Cuentos originales son de lo mejor que se ha escrito en el género en México, dice un crítico mexicano. Juan Valera declara que como cuentista el ingenio, el talento y la habilidad para narrar están realzados por la naturalidad del estilo y por la gracia y el primor de un lenguaje castizo y puro. Vicente Riva Palacio, activo militar que luchó en las fuerzas de Juárez, escribió historia, crítica, poesía, novela, periodismo y cuentos. Es más conocido como cuentista por sus Cuentos del general.

Los cuentistas mexicanos de las nuevas generaciones datan del año 1910, fecha memorable en la historia de México y que marca de una manera inconfundible la línea divisoria de la generación del siglo xix y la contemporánea. Pero tanto los cuentistas anteriores a 1910, como los del nuevo México, todos han bebido del mismo manantial: en la agonía de un pueblo siempre en lucha pero con la fe y la esperanza del que ve el faro de salvación a corta distancia. Estos afanes del pueblo mexicano dan al cuento una tendencia realista. José López-Portillo y Rafael Delgado, dos buenos novelistas, introducen en el cuento mexicano personalidad propia, que convierten sus relatos en verdaderos cuentos. López-Portillo, oriundo de Jalisco, pinta en novelas y cuentos el alma de su patria chica. Ensaya la narración corta antes de emprender la novela. Posee frescura 
de estilo, corrección de forma, y sus obras están llenas de vida. Sus obras menores son Seis leyendas, Novelas cortas, Historias, historietas y cuentecillos. Entre sus más conocidos cuentos merecen citarse Ramo de Olizo, Reloj sin dueño, La horma de un zapato, y el mejor de todos: El billete de lotería. Rafael Delgado goza de reputación como novelista, poeta y autor dramático. Su novela más famosa es La Calandria. La mayoría de sus cuentos son una pintura complaciente del ambiente de la costa veracruzana. Sigue la tradición realista de Pereda. Cuentos y notas es su mejor colección de cuentos, y El desertor seguramente el mejor de ellos. Manuel Gutiérrez. Nájera no sólo fué poeta sino cuentista excelente. Con Rubén Darío da nuevas emociones al cuento. Su cuento Historia de un peso falso es obra maestra en sí. Sus Cuentos frágiles y Cuentos colon de humo, son ejemplos de cuentos dolorosos y escépticos. Angel de Campo (Micrós) pinta en sus $C$ uentos, con verdadero amor, la vida de la clase media y baja de México, con todo su dolor y miseria. Amado Nervo es cuentista lírico y modernista que busca la expresión individual, como es evidente en Una esperanza, tal vez su mejor cuento. Los Cuentos románticos de Justò Sierra constituyen un dato importante en la evolución de las letras mexicanas. Son obras de su juventud, relatos novelescos publicados en revistas y periódicos, que el propio autor llama "poemillas en prosa impregnados de lirismo sentimental y delirante." Cayetano Rodríguez Beltrán, de Veracruz como Delgado, fué discípulo directo de éste. Hizo placas fotográficas de tipos y escenas de su región natal. Se dió a conocer con Una docena de cuentos, Cuentos costeños, Cuentos y tipos callejeros. Abigeo es uno de sus mejores cuentos. El poeta y crítico Luis G. Urbina también escribió cuentos que los reunló en Cuentos vividos y crónicas soñadas, escritos en prosa atildada, flexible, rica en matices, pródiga en imágenes.

La nueva generación de cuentistas mexicanos es numerosa y prolifica. Su afán general es buscar un ideal de raza, y en esta tarea tan enaltecedora es digno de mención Francisco Monterde, t infatigable literato $y$ profesor que revela un gran conocimiento del ambiente, en sus famosos cuentos La moneda de oro, El farastero, $y$ otros. También ha escrita simpáticos cuentos de hadas. Gregorio López y Fuentes, conocido más por novelista, se interesa por el indio oprimida por el blanco y sus artimañas para esclavizarlo; 
casi siempre llevan sus cuentos un fin moral. Además de su famosa novela $\mathrm{El}$ indio, en el género del cuento ha escrito Cuentos campesinos de México, entre los que sobresalen Una carta a Dios, Iusticia, La sabiduria, La inconformidad, y otros, todos escritos en un lenguaje popular y directo. También el novelista doctor Mariano Azuela escribe cuentos en los que le preocupan no sólo la revolución sino el trabajador, la clase trabajadora. Martín Luis Guzmán, también ha hecho lo mismo que Azuela. El Dr. Atl (Gerardo Murillo) se interesa por la aventura y el misterio, sobre todo entre los indios, como se nota en Cuentos de todos colores. El hombre y la perla es su cuento más popular. Ermilo Abreu Gómez es más bien escritor del folklore literario en sus Cuentos de Juan Pirulero, en los que este personaje representa el protector del pobre; Tres nuevos cuentos de Juan Pirulero. Dos de sus más conocidos son Asi era entonces y Pescadores. También hay que mencionat en esta rápida reseña a Jorge Ferretis, interesado en reformas sociales, según vemos en Hombres en tempestad. Rafael Muñoz escribe sobre la revolución mexicana en Servicio de patrulla, El hombre malo, El buen bebedor. Jesús Millán se concreta a la descripción de luchas y conflictos, muertes, heroísmo en las campañas militares en que el autor tomó parte. Esto se ve en La carta de un prisionero, El traidor, etc. Celestimo Herrera Frimont también se preocupa por la revolución, como Millán. Casi siempre relata el heroísmo y peripecias del soldado. Entre sus más conocidos cuentos pueden citarse El fusilado y La gaucha. Antonio Acevedo Escobedo, escritor realista, en tono de conversación relata, en el local de un café Un alma de Dios. Pero Memorias del 595 es uno de sus mejores cuentos, chispeante y gracioso, de una locomotora rota e inservible, que recuerda su activa vida en tiempos pasados. Gilberto F. Aguilar publicó Diez cuentos, en los que trata de la gente humilde. El papelero versa sobre un muchacho de padre desconocido que cae at un tranvía al querer subir para vender periódicos; muere en el hospital con un retrato de su madre en la mano. César Garizurieta es seguramente el cuerrtista contemporáneo de mejor humor y de un sentido de humor libre de ironía o sarcasmo, como es patente en Un agujero en el aapata y en El apóstol del ocio de su albedrío de su colección titulada El diablo, el cura y otros engaños. Francisco Rojas González escribe de todo aquello que of rezca tema para sus cuentos. Es tal vez el cuen- 
tista más popular en la actualidad. Cuentos de ayer y de hoy aparecieron en revistas y periódicos. El pajareador es su cuento más conocido. Rojas González, por su vasto panorama de la vida mexicana en su obra, presenta al verdadero pueblo mexicano, como ha dicho uno de sus críticos. $Y$ a propósito de críticos, no hay que olvidar a Julio Jiménez Rueda, bien conocido crítico literario, pero que también ha hecho teatro, novela y cuento. Su primer libro fué, en efecto, Cuentos y diálogos. Su fuerte es, sin embargo, el drama. El educador José Vasconcelos escribe cuentos de imaginación y con elementos sobrenaturales (El fusilado), y Alfonso Reyes, cuentos personales, como lo hace en La primera confesión, precioso relato de su primera confesión.

En México, así como én Argentina, se está desarrollando rápidamente el cuento policiaco, en gran parte por la influencia que - las traducciones detectivescas han tenido en esas dos repúblicas. En México, Rafael Bernal es uno de los mejores cultivadores del género. Un muerto en la tumba y Tres novelas policiacas le colocan entre los mejores Conan Doyles hispanoamericanos.

En la América Central la República de Guatemala inspira narraciones de tema maya e indígena, mientras que en las demás regiones de Centro América las costumbres y el paisaje sirven de fondo al cuento de esta parte del continente. El guatemalteco Máximo Soto Hall es escritor multiforme, político, crítico, cuentista, imitador de Heine y Bécquer. Ha publicado Dibujos y bronces, libro de cuentos y semblanzas. Carlos Wyld Ospina, poeta de reconocida reputación, es además ensayista de sociología y cuentista. La tierra de las nahuyacas le ha destacado como cuentista, sobre todo con relatos como La mala hembra, El manuscrito de Fernán Avelino. Francisco Barnoya Gálvez también se interesa en problemas del indígena en Han de estar y estarán, colección de tradiciunes y leyendas guatemaltecas. La mariposa negra es uno de sus mejores cuentos. Rafael Arévalo Martínez, cunocido autor de El hombre que parecía un caballo, también se ha acreditado como cuentista, sobre todo en su colección $E l$ señor Monitot, en cuyos cuentos sobresalen el sufrimiento y el dolor de los indígenas. Flavio Herrera posee una fuerza extraordinaria de expresión en sus cuentos. Le encantan las imágenes y la metáfora y su estilo es brillante y poemático. La lente opaca es su mejor colecciön. Miguel Angel Asturias, autor de Leyendas de Guatemala, 
describe una América Central creyente, pintoresca, folklórica y tradicional. Ha sido traducida esta obra al francés. El hermano Pedro es un breve cuento de dicho libro.

La diminuta república de El Salvador también tiene sus buenos representantes en el cuento. Salvador Salazar Arrué, que firma "Salarrué" está interesado en las costumbres de la clase media salvadoreña, como lo manifiesta en Cuentos de barro, llenos de color local. La brasa y La brusquita, Bajo la luna, La petaca, y algún otro, son conocidos por su sabor a la manigua centroamericana. José María Peralta es militar y escritor costumbrista de buena estirpe. Sus cuentos están repletos de humor y gracia. Sus mejores colecciones son Brochazos y La muerte de la tórtola. Arturo Ambrogi publicó mucho en periódicos, que recogió en Libro del trópico, colección de cuentos. Eugenia de Valcácer recibió en 1941 el primer premio en el Gran Concurso Literario de San Salvador, entre 59 concursantes, con el cuento La botija.

En Honduras merecen citarse a Arturo Mejía Nieto, cuyos relatos han aportado un caudal al folklore americano. En su colección El solterón sobresale el hermoso cuento La culebra. Froilán Turcios, político y diplomático, ha escrito en revistas y periódicos. Su mejor cuento es El vampiro y su mejor libro es Cuentos del amor y de la muerte. Marcos Carias Reyes, también político y diplomático, se ha hecho notable con sus varios volúmenes de cuentos: Cuentos de lobos, Cuentos de perros, Cuentos de gatos. $\mathrm{Y}$ por último, Arturo Martínez Galvido ha cultivado la novela y el cuento, pero con más éxito este último género. Murió muy joven, pero dejó prueba fecunda de su valer literario en Desvario.

En Nicaragua no hay necesidad de detenernos con Rubén Darío, poeta de América, pero también cultivador del cuento (La muerte de la emperatriz de la China, etc.) Su obra es conocida de todos. Santiago Argüello es un distinguido escritor que ocupó importantes cargos en su país, viajó extensamente y escribió obras de variado género. Una de sus colecciones de cuentos es El libro de los apólogos.

En Costa Rica hay varios nombres que sobresalen como cuentistas. Manuel González Zeledón, que usa el seudónimo de "Mogón” es cuentista de gran vivacidad. Publicó sus cuentos en periódicos de su patria, estableciendo reputación con La propia, uno de sus mejores cuentos. María Isabel Carvajal, que se firma "Carmen 
Lira" se distingue por sus cuentos sencillos, en los que reluce la espontaneidad; gracia y frescura. Son conocidos sus Cuentos de la tía Panchita. Y finalmente merece mencionarse a Ricardo Fernández Guardia quien evoca las grandezas del pasado colonial de su patria en sus bien conocidos Cuentos ticos y Crónicas coloniales, llenos de colorido y sobriedad, y de estilo sencillo y pulcro.

Llegando a Colombia en nuestro recorrido al apuntar esta breve reseña del cuento hispanoamericano, vemos que en el pais de Magdalena el cuentista está más preocupado por lo estético que por lo autóctono. Parece ser que Colombia está absorbida por la poesía, la historia y la crítica, géneros que atarean a sus mejores intelectuales, como ha declarado Luis Alberto Sánchez. El antioqueño Jesús del Corral, de fácil y graciosa palabra, ocupa un puesto envidiable como cuentista de las costumbres de su patria chica. Célebres son sus relatos Que pase el aserrador, El huracán de Enciso, El ingeniero de Lieja, y otros. También antioqueño, Efe Gómez ocupa un lugar elevado entre los escritores de su región por sus cuentos y novelas cortas. Es original, posee brío, nervio potente y masculinidad en el estilo, según un crítico colombiano. Entre sus famosos cuentos figuran El paisano Alvarez Gaviria, Un padre de la patria, Guayabo negro. Tomás Carrasquilla se dió a conocer en Medellín, su pueblo natal, mediante bellos cuentos regionales. Inventó el personaje Simón el Mago, que le hizo adquirir fama en todo el pais, y más tarde en toda la América. Escribió varias novelas de reconocido mérito. Como cuentista son famosos sus Cuentos de tejas arri$b a$. Max Grillo, natural de Manizales, es ante todo poeta de la naturaleza. Sin embargo, ha escrito páginas descriptivas en prosa de gran fuerza y relieve de estilo, como Alma dispersa, colección de cuentos y ensayos. José María Vargas Vila es bien conocido en el extranjero. Fué prolífico, multiforme; su obra es sin embargo, sonora, colorida, deslumbradora. Mis mejores cuentos le colocan entre los mejores cuentistas. La esposa del literato José María Samper, Soledad Acosta de Samper, fué cuentista a lo Fernán Caballero, Escogió los temas históricos, los recuerdos de familia y las costumbres de Colombia para temas de sus obras. Luz y sombra es una colección de cuentos de este tipo. Un dentista de profesión, Eduardo Aria Suárez, que se firma "Constantino Pla" ha adquirido nombradía como uno de los más felices cultivadores del cuento en Colombia. 
$\mathrm{Ha}$ publicado sus mejores cuentos en periódicos y revistas. Sabe describir con precisión y vivacidad, y posee gran dominio del diálogo y aguda penetración psicológica. En sus Cuentos espirituales hace gala de una agradable y aguda penetración del ser humano. Su cuento Los pijamas le ha hecho famoso, aunque $S e$ vende un canario y Envejecer no le van en zaga. Abel López Gómez ha publicado varios tomos de cuentos, entre los que sobresalen Por las calles de la tierra, El fugitivo y El hombre, la mujer y la noche. Luis Tablanca es un artista de la narración en prosa castiza y flexible. Sus cuentos están llenos de paisajes y colorido, como se muestra en Cuentos sencillos y Cuentos fugaces.

Por razones geográficas, al cuentista de la república de Venezuela le preocupan los llaneros y la vida libre y montaraz que llevan en las sabanas. Los escritores románticos y los neoclásicos venezolanos habían escrito narraciones e imitaciones de leyendas francesas, pero una fecha más precisa sería allá por 1896 cuando empieza el cuento en Venezuela. En la actualidad el cuento se ha desarrollado inesperadamente. Luis Urbaneja Achelpol es, de todo rigor, el primer cuentista venezolano. En 1896 aparecieron sus primeros cuentos en la revista $E l$ cojo ilustrado, los que reflejan escenas de costumbres del país, con voces y color locales. Los cuentos de Urbaneja tratan de la existencia criolla, sin alegría pero sin amargura. Sus cuentos son de lo más fresco y vivo de la literatura venezolana. También de la misma fecha que los cuentos de Urbaneja son Confidencias y Psiquis de Manuel Díaz Rodríguez, cuentista modernista de gusto francés. Otro de sus libros de cuentos es Cuentos de color. Más conocido fuera de Venezuela es Rufino Blanco-Fombona, hombre culto, aventurero y andariego, que se distinguió como crítico, novelista y poeta más que como cuentista. Sin embargo, ¿qué hispanohablante no ha leído El Catire, uno de los mejores cuentos de Hispano América? Sus cuentos son rápidos y dramáticos, estampas de violencia, como ha dicho Uslar Pietri. Las colecciones más importantes de Blanco-Fombona son Cuentos de poeta, Más allá de los horizontes y Cuentos americanos. El muy querido literato, fallecido en 1949, Pedro Emilio Coll, hombre culto que ejerció gran influencia en la literatura venezolana, no escribió mucho, pero su obra es de acendrada calidad. El diente roto, breve joya antológica, relato de un hombre que se vuelve célebre sólo porque se calla, 
para ocultar una mella en un diente, le ha hecho famosísimo en toda la América Hispana. Palabras es una colección de cuentos, mientras que Las divinas personas son relatos. Sus ensayos y cuentos más conocidos están en dos tomos El castillo de Elsinor y La escondida senda. Más conocido fuera de Venezuela en tiempos actuales es Rómulo Gallegos, cuentista y novelista de gran renombre y ex presidente de Venezuela. Los aventureros es una colección de cuentos aparecidos en revistas y periódicos, entre los que se incluye, además del que le da título El apoyo, La liberación, Sol de antaño, etc. Jesús Enrique Lossada cultiva el cuento semi-científico, como La máquina de la felicidad; y el conocido novelista y cuentista Arturo Uslar Pietri se ha dado a conocer con Las lanzas coloradas, pero tal vez sea superior en sus cuentos. Su mejor libro en este género es Barrabás y otros relatos, muchos de los cuales habían aparecido en publicaciones periódicas.

Algunos jóvenes cuentistas venezolanos que merecen citarse de pasada son Leoncio Martínez, que escribe con el seudónimo de "Leo". Mis otros fantoches es su obra maestra. José Rafael Pocaterra, de estilo rápido, dramático y directo, ha publicado Cuentos grotescos, entre los que se destacan El chubasco, La latina, Los corremuertos y otros. $\mathrm{Y}$ no terminaremos esta sección dedicada a Venezuela sin mencionar a Andrés Eloy Blanco, Vicente Fuentes, Pedro Sotillo, Mariano Picón Salas, Carlos Eduardo Frías, Guillermo Meneses, Ramón Díaz Suárez, Julián Padrón, Gustavo Díaz Solís $y$ otros muchos que es imposible citar.

En Ecuador el cuento de Los tres cuervos, de José Antonio Campos, es conocido hasta de los niños de corta edad. Es este cuento una obra acaba de las más graciosas de la literatura hispánica. Trata de una serie de transmisiones orales, dadas de una persona a otra, con motivo de la enfermedad de un soldado y los tres cuervos que dizque un enfermo soldado ha vomitado, resultan ser mera referencia al color negro, negro como el ala de un cuervo. ¿Qué otro cuento hispanoamericano muestra la innata tendencia andaluza e hispanoamericana de la exageración? Campos ha escrito otros graciosos relatos de costumbres de su país, publicados en revistas y periódicos, y reunidos en Cintas alegres, Rayos católicos y fuegos fatuos, y otras colecciones. Juan León Mera, el célebre autor de Cumandá, también fué el autor del himnn nacional del Ecuador. 
Escribió poesia, leyendas, crítica e historia. Antes de publicar su famosa novela se dió a conocer con novelitas como Entre dos tías y un tio, Porque soy cristiano y otros relatos coleccionados mucho después de su publicación. La desgracia del indio Pedro es uno de sus mejores cuentos. José de la Cuadra, también ecuatoriano, cultivó el cuento y la novela en cuyos géneros recogió los aspectos costumbrísticos de los montuvios ectuatorianos. Escribió cuentos largos y novelas cortas, que le han hecho famoso en toda la América Española. Son obras de este género Cuentos de alta mar, La vuelta de la locura, Cuentos de las islas de los Galápagos, El amor que dormia, Horno, y otros libros. Es de la Cuadra escritor patético, rebelde al medio social; todos sus relatos están llenos de realismo, emoción y arte. Enrique Gil Gilbert recibió segundo premio en Nueva York por su novela Nuestro pan. Sus libros de cuentos Los que se van y $Y$ unga ponen de manifiesto vigor en los relatos, colorido y verdadera realidad. José Gallego Lara colaboró con el anterior en Los que se van, pero quien a su vez ha escrito por separado cuentos de mérito. Demetrio Aguilera Malta cultivó el cuento un tanto, pero es más bien novelista y dramaturgo.

En los países indianistas, como el Perú, Bolivia y México, donde predomina el elemento indígena, los cuentistas, naturalmente, escriben sobre todo del indio y sus problemas, poniéndonos de manifiesto en vivos colores, sus vestimentas, sus costumbres, su relación precaria con el blanco, sus creencias e interesantes aspectos culturales y sociales. En el Perú las Tradiciones peruanas de Ricardo Palma sirven de modelo para el cuento moderno no sólo en esa región sino en otras lejanas partes del continente. Es verdad que los relatos de Palma tienen un fondo histórico o semi-histórico, lo que dificulta su clasificación como cuentos; pero por su gracejo y elaboración, fantasía, vida auténtica y casticismo, poseen esas "tradiciones" un valor artístico, ya que han sido reconocidos como los mejores cuentos hispanoamericanos del siglo xix. Principió Palma a recoger sus famosas tradiciones desde 1863. Palma, por su temperamento y carácter, encontró en las tradiciones orales y escritas del Perú una mina inagotable de material que coincidía con su espíritu y que le inspiró arriba de diez tomos. Lo notable de la obra de Palma es que no sintió ni pudo sentir al indio, por el simple hecho de que la preocupación por el indio viene más tarde. Palma buscó motivos que podía 
sentir e interpretar. Buscó lo curioso, lo gracioso y lo pintoresco en el pasado del Perú, aunque a veces tocaba lo heroico. $Y$ entre sus hermosos relatos ¿quién no ha gozado de los encantos de La camisa de Margarita, Muertos en vida, La cajetilla de cigarros, El alacrán de fray Gómez, y otros.

El peruano Manuel Beingolea está considerado como el mejor cuentista đe su generación. No es romántico, pero sí un sentimental que disfraza su queja haciendo alardes de ironía. Entre sus mejotes cuentos están $M i$ corbata y Levitación. Su mejor colección es Cuentos pretéritos. Clemente Palma, en vez de seguir a su distinguido padre, le vemos ambular por el extranjero en Cuentos malévolos, que han dejado huella en el Perú. El libro de cuentos El caballero Carmelo de Abraham Valdelomar está considerado como una colección de cuentos perfectos. Los de temas incaicos fueron reunidos póstumamente bajo el título de Los hijos del sol. Es Valdelomar el más grande cuentista peruano después de Palma, y según algunos el precursor de la nueva literatura peruana. Reivindicó lo criollo, camino en que le siguieron otros paisanos suyos. Ventura García Calderón, aunque muy francés, ha escrito desde París cuentos de sabor y colorido superiores de asuntos del Perú, como es el conocidísimo El alfiler. Se inició en cuentos incaicos con La venganza del cóndor, tema que continuó en Le sang plus vite, Couleur du sang, y otros. Posee García Calderón un don de estilo y una gracia para el relato nada común. Enrique López Albujar es buen conocedor del problema del indio y de la serranía, pues es oriundo de ésta. Su afecto por el indio se evidencia en Cuentos andinos. Otras colecciones suyas son: De mi casona, Los caballeros del delito, Nuevos cuentos andinos. En estos cuentos habla del sufrimiento, miseria, horror $y$ crueldad en que viven sus personajes. Ciro Alegria, José Díez Canseco y María Wiesse también se preocupan por el indio. Alegría es ante todo novelista, pero ha escrito cuentos de estilo fácil y elegante. A Díez Canseco le atrae la nota mulata y zamba (Jujuna), mientras que Wiesse busca la ironía en el indio, como lo hace en Quipus. Carolina Denegri, sin embargo, busca la ternura en el indio, lo mismo que quiere hacer José María Aguedas, joven cuentista que también trata del hombre de la sierra, como se ve en Agua, su primer libro de cuentos que promete mucho. Felipe Sassone, de origen italiano, novelista de tipo erótico, ha cultivado también el cuento en Pizarro 
en la Isla del Gallo, una de sus mejores narraciones. Alberto Guillén publicó poco antes de morir en 1936 Leyenda patria, entre cuyos cuentos se destaca El sueño del tejedor. Otros cuentistas de actualidad reciente son Lizandro Luna, Manuel Tamayo, Arturo Jiménez Barja, Fernando Romero, Armando Bazán, Adalberto Vasallanar, etc.

El cuento de Bolivia aparece con la nueva generación de jóvenes escritores, allá por los años 1914 y 1915. Ese grupo de jóvenes inyectó una nueva fuerza en la literatura del país. Tras esta generación llegó otra años más tarde, trayendo renovador impúlso y una misión más precisa de las cosas nacionales. Rosendo Villalobos pertenece al grupo renovador. Peca de mucha influencia francesa y representa la narración del altiplano. De su libro Pedazos de papel sobresale Sor Natalia. Ricardo Jaimes Freyre es excelente cuentista que publicó buen número de sus cuentos en revistas y periódicos. Fué el primer representante del movimiento modernista de Bolivia. Uno de sus mejores cuentos es Justicia india, publicado en La Gaceta de Bolivia. Augusto Céspedes s̀e ve absorbido con la guerra del Chaco, durante la cual compuso Sangre de mestizos, una novela vertebrada en crónicas de intenso dramatismo. El relato intitulado $E l$ pozo, es un estudio psicológico y fisiológico de la sed tremenda del Chaco. La coronela, La paraguaya, y otros son episodios vivientes y enérgicos. Juan Francisco Bedregal, poeta, crítico y cuentista, ama el campo y la naturaleza. En su libro Figuras animadas se en'cuentra Don Quijote en la ciudad de la Paz, cuento de gran ingenio. Abel Alarcón se ha destacado por completo en las letras de su patria. Ha traducido obras extranjeras y ha hecho crítica. Sus colecciones de cuentos son De mi tierra y de mi alma, Cuentos del alto Perú, de los que hay que recordar La cogida y Los dos jinetes. También interesado en el indio es Alcides Arguedas, político y diplomático que ha logrado describir de manera vigorosa las costumbres y la resignación del indio de Bolivia. Venganza aymara es un buen ejemplo de su estilo.

Los cuentos de Chile están llenos de salitre y mezclados con sangre araucana. Los campos es el escenario favorito de los cuentistas chilenos. El suburbio, la clase media, la vida rústica, con todos sus problemas sociales y pasionales dan ocasión a dramitas de la clase aburguesada. Sólo por excepción pintan los cuentistas chilenos otra clase de gente. La existencia marítima también sirve de 
fondo a algunos cuentos. A pesar de la expresión propiamente chilena, se ven, de vez en cuando, corrientes extranjeras en el cuento chileno, fenómeno desnatural en un país tan aislado como Chile. Se podría declarar, sin grave exposición a error, que el primer cuentista chileno, por lo menos el precursor del cuento, fué José Victorino Lastảrria. Este escritor aclimató en Chile, en 1843, este género literario al escribir El mendigo. Los cuentos de Lastarria revelan influencia castellana, aunque sus sentimientos e ideas son los de la época, es decir, románticos. Coleccionó sus cuentos en Antaño y ogaño, subtitulados Novelas y cuentos de la vida hispanoamericana, editados en 1885.

Joaquín Díaz Garcés escribió en muchas revistas, empleando el pseudónimo "Angel Pino", con el cual suscribió todos sus cuentos y muchos artículos humanísticos. Páginas chilenas es una colección de los mejores y genuinamente chilenos, y Juan Neira es uno de sus mejores cuentos. Emilio Rodríguez Mendoza, amigo e imitador de Dario, cultivó el cuento fantástico, en el que el héroe es ya una flor, un insecto, la brisa o el rocío, como en Gotas de absintio, una de sus mejores colecciones. Rafael Maluenda está preocupado principalmente con la gente humilde de su país en Escenas de la vida campestre. Aquí es donde aparece en todo su relieve este tipo tan chileno, el roto, es decir el gaucho chileno, protagonista de gran número de cuentos y novelas. Maluenda posee una rica imaginación creativa y pictórica. Escribe en una lengua ágil y robusta. $V$ enidos a menos, es un tomo de cuentos y novelitas. Federico Gana pasó una vida bohemia en los barcos de Santiago de Chile. Se le considera como el iniciador del cuento campesino, en el que retrata la vida de esos chilenos socarrones, enredosos, patriotas, violentos y desconfiados con exquisito gusto, como lo muestra en Días de campo, Manchas de color y otros cuentos, entre los que sobresale La señora. Buen observador del carácter nacional fué Manuel J. Ortiz, quien publicó la mayor parte de sus cuentos en publicaciones periódicas. Cartas de la aldea es una colección de escenas inspiradas cuando el autor era maestro de escuela en un distrito rural. Aquí vemos al "guaso", tipo chileno siempre en la defensiva, pero lleno de humor, parlanchín y dicharachero. Marta Brunet se inspira en el campo, cuya realidad es para ella una emoción poemática inolvidable. Las escenas que describe, por ejemplo en Reloj de sol, pasan 
en el campo del sur de Chile y los personajes son rústicos y labriegos, descritos en bellas páginas. También ha escrito novelas cortas. Dos de sus cuentos más populares son Doña Santitos y Don Florisondo. A Mariano Latorre le ha atraido la tierra y el campo, y está conceptuado como el más completo en la literatura descriptiva de Chile. Es quizá Latorre el que ha profundizado con más energía en la pintura del ambiente exclusivamente chileno. Hombres y zorros son cuentos llenos de colorido; Cuentos de Maule es una colección de siete relatos largos, mientras que Chilenos del mar se considera como su obra maestra en este género. Augusto D'Halmar ha estado en el servicio diplomático y viajado extensamente en Europa. De La lámpara en el molino el mejor cuento es En provincia, premiado en Madrid al aparecer por primera vez.

Joaquín Edwards Bello es bien conocido fuera de Chile. Es más narrador que cuentista $\mathrm{y}$ se ha distinguido como gran novelista. Cuentos de todos colores, en que está El bandido, uno de los mejores, es su colección más popular. La carrera literaria de Manuel Rojas comenzó con su libro de cuentos Hombres del sur, del cual $E l$ colocolo es uno de los mejores. Su segundo libro de cuentos $E l$ delincuente constiuye una de las mejores obras en su género de la actual literatura chilena. Bien conocido es su cuento $\mathrm{El}$ cachorro. Baldomero Lillo vivió mucho en la región de las salitreras, en el norte, donde tuvo oportunidad de estudiar las miserias y dolores de los obreros. Es uno de los mejores cuentistas sudamericanos contemporáneos. Sus tres obras más importantes son Relatos populares, Sub sole y Sub terra, donde pinta los sufrimientos, los amores, las angustias y las hazañas de campesinos, indios, mineros y vagabundos. Angel Custodio Espejo también ha cultivado el cuento naturalista en Cuentos de alcoba. Prefiere el ambiente elegante y da la impresión de intencionadas descripciones de vicio de la alta burguesía. Escritor de la vida del campo es Guillermo Labarca Hubertson, que ha publicado muy poco, una novela y Al amor de la tierra, cuentos naturalistas. Cuentistas más recientes que sólo mencionaremos de nombre son Osvaldo Wegmann, Juan Gómez, Leoncio Guerrero, Benjamin Subercaseaux, Carlos Acuña y Fernando Santiván. Este último está afanado por las tragedias y la amargura del campero chileno, como se manifiesta en Palpitaciones de vida. 
En la Argentina predominan la pampa y Buenos Aires y de ahí que el cuento argentino tenga como tema central al gaucho y al porteño. El conflicto entre el porteño y el gaucho, es decir, entre la urbe y lo campesino, o entre la civilización y la barbarie, ha dado origen a múltiples cuentos en Argentina y Uruguay. El cuento rioplatense es reciente; es mucho más tardío que en los Andes y en México. Los virreinatos del Perú y México ofrecieron al literato desde más remotos tiempos temas de inspiración. La región del Rio de la Plata fué, durante los siglos del coloniaje, región dedicada a la cría de animales. $Y$ en un país así constituído, poblado por ganaderos y soldados, la cultura intelectual se desarrolló tardíamente y en una forma más lenta que en otras partes del continente. $Y$ sin embargo, a pesar de su tardía aparición como género literario, el cuento de la Argentina y del Uruguay se ha desarrollado con vigor, gracias en gran parte a mejores medios editoriales y mayor público leyente.

Fuera del caso especial de Horacio Quiroga, que pertenece a la región literaria y lingüística rioplatense, el cuento argentino ha ido siguiendo la trayectoria y evolución de la novela. Esto se debe, seguramente, a que los mejores cuentistas argentinos son novelistas, y viceversa. Por otra parte, hay obras, como El matadero de Echeverría, que por su brevedad se ha clasificado como cuento. A pesar de estos antecedentes se podría precisar que el cuento se desarrolla y populariza hacia fines del siglo xIx. El escritor amenísimo y periodista sagaz, José S. Alvarez, conocido por el seudónimo de "Fray Mocho" se dió a conocer con sus descripciones de tipos populares, stus sátiras agudas contra los pecadós y delitos de la política. Más que cuentos son sus narraciones trozos de realidad, escenas de la vida, costumbres y tipos de la gauchería argentina y del ambiente porteño. Diestro cuentista, publicó numerosas colaboraciones de este género en revistas y diarios. Fray Mocho es autor cómico, que publicaba sus graciosos cuadros en Caras y Caretas, revista por él fundada. Fué este autor un verdadero humorista, pero de un humorismo con simpatía y amor por sus caracteres. Todos sus libros han alcanzado merecido éxito: Viaje al país de los matreros, Cuentos de Fray Mocho, Memorias de un vigilante, La caza del cóndor, En el mar austral, Salero criollo. Arturo Cancela en Tres relatos porteños logra revelar un humorismo de buena cepa, maestría del 
idioma y una buena técnica al ofrecernos múltiples aspectos tragicómicos de la vída de la ciudad. Elías Castelnuovo, por otra parte, ve el lado tétrico, pesimista del ambiente bonaerense, en sus Malditos, Tinieblas, Entre los muertos, Carne de cañón y otros libros. E1 cuento Reformatorio es seguramente el mejor de todos. Castelnuovo es un prosista social, interesado en la descomposición y desnivel social. Los cuentos de Víctor Juan Guillot poseen un tinte de influencia rusa. Sus mejores obras son Historias sin importancia, El alma en el pozo, El vado, Terror. Alvaro Melián Lafinur se inspira en motivos orientales para su tomo de cuentos Las nietas de Cleopatra. Martiniano P. Leguizamón escribió varios tomos de cuentos realistas del gaucho argentino (Recuerdos de la tierra, Mis montañas y Calandria).

Escritores más conocidos fuera de Argentina a causa de sus publicaciones amén del cuento son el novelista Benito Lynch, que hubiera logrado puesto de honor sólo con El potrillo roano, de su colección De los campos porteños. Manuel Ugarte, incansable viajero, ha estudiado la literatura francesa y española y se puede clasificar como cosmopolita. Aunque se sale con frecuencia de su propio terruño, en novelas y cuentos, ha dedicado muchos cuentos a la Argentina. Ha reunido éstos en Cuentos de la Pampa, de los que El curandero es encantador; Cuentos argentinos; y Una tarde de otoño. Manuel Rojas, trotamundos, buen conocedor de los Andes chileno-argentinos, se dió a conocer extensamente con Hombres del sur. Además ha publicado Lanchas, La bahia, La ciudad de los Césares, etc. Alberto Gerchunoff, es judío, interesado en su propia raza, como se ve en Los gauchos judios, Cuentos de Azar. Este culto autor escribe con vigor, revelando potente fuerza de observación, agudeza y gran sentido de la palabra. La lechuza es seguramente su más conocido cuento.

Otros escritores que vienen cultivando el cuento con felicidad son Juan Carlos Dávalos, conocido por sus cuentos sobre costumbres argentinas. Pinta leyendas de su provincia en un estilo sencillo y nada afectado. Su cuento Noche campestre le ha hecho famoso. Justo P. Sáez (hijo), autor de cuentos y relatos camperos, posee gran conocimiento de la vida rural. Su mejor obra es Pasto Puna y Baguales. Liboria Justo, se ha dedicado a describir la vida $y$ las 
costumbres de distintas regiones del país, en La tierra maldita, con agudo sentido de observación y eficaces colores.

Tres escritores argentinos contemporáneos que cultivan el cuento con verdadero éxito, aunque se han dado a conocer con sus novelas son Hugo Wast (La yegua mora), Ricardo Güiraldes (Cuentos de muerte y de sangre) y Eduardo Mallea, cuyos Cuentos para una inglesa desesperada le colocan entre los cuentistas de primer rango. Para terminar habría que mencionar a Alberto Ghiraldo y a Héctor Pedro Blomberg, también cuentistas de nota.

El cuento del Uruguay, nuestro último país en este recorrido literario, está inspirado, casi en su totalidad, en asuntos del campo, con la inevitable presencia del gaucho y del paisano. El cuento del Uruguay no aparece en el horizonte literario hasta llegadas las postrimerias del siglo XIX, como ocurre con el argentino. Lo que se dijo sobre este género literario acerca del argentino, se aplica también al cuento uruguayo. Los cuentistas del Uruguay verdaderamente son del siglo $\mathrm{xx}$, pues antes de este siglo sólo hubo poetas, críticos, novelistas y dramaturgos.

La campaña del Río de la Plata, con sus supuestos gauchos de facón y guitarra, sus peones de estancia, y chacreros, han sido presentados al lector en casi todas las formas de género literario. Y lo mismo que Buenos Aires sirve de escena al porteño, en el caso del Uruguay la capital Montevideo da vida a escenas de personajes típicos de las barriadas, o al ambiente de las playas de moda. Tal vez el primer cuentista uruguayo, y uno de los mejores cuentistas del alma de los campesinos rioplatenses, si no el mejor, sea Javier de Viana, fuerte y colorido como los antiguos gauchos que él mismo describe. Vivió en Buenos Aires largo tiempo y dejó huellas profundas en ambos lados del Plata. Le preocupa la vida y el alma intima del gaucho; es un psicólogo con admirable facilidad de condensación. Su interpretación es sincera y real, aunque a veces su realismo produce extrañeza y ciertá repugnancia. Entre sus colecciones de cuentos merecen citarse Campo, Macahines, Yuyos, Leña seca, Cardos.

El cuentista más popular del Uruguay, sin embargo, es, sin duda, Horacio Quiroga, cuyos cuentos son conocidos de todo hispano-leyente, incluso miles de estudiantes de español de los Estados Unidos. Quiroga y Ricardo Palma son los dos cuentistas hispano- 
americanos mejor conocidos en el extranjero. Aunque Quiroga escribió novelas, es fundamentalmente cuentista e inconfundiblemente escritor de cuentos. Quiroga conoce como pocos el alma del gaucho argentino y uruguayo. Entiende, sobre todo, de almas femeninas, y posee un profundo sentido de lo vital y dinámico en los seres y en las cosas. Muestra marcada preferencia por tipos anormales, sobre todo citadinos. Quiroga descubre un mundo inexplorado, hasta entonces semisalvaje: el agua y la selva, la fauna y los habitantes primitivos de Argentina y Uruguay. Sus narraciones abarcan una extensa gama literaria, desde la tragedia al humorismo. Conoce la vida del campo y de la ciudad. Algunos de sus cuentos, $A$ la deriva, El solitario, El perro rabioso, son todo un drama completo. Sus cuentos de ambiente misionero y paranaense son insuperables, como lo hacen ver $U n$ peón y $E l$ yaciyateré. Cuentos con protagonistas animales, tales como El alambre de púa, de Cuentos de la selva, fueron escritos expresamente para niños y de difícil superación. Sus colecciones más famosas son: Más allá, Cuentos de amor, de la casa y de muerte, El desierto, El crimen del otro, Amor pasado, La gallina degollada y otros cuentos.

Eduardo Acevedo Díaz fué fundamentalmente novelista uruguayo aunque escribió cuentos, que no reunió en un volumen, pero de ellos merece citarse $A$ correr sortija. Vicente A. Salaverri fué periodista infatigable, novelista y cuentista destacado. Al revés de sus novelas, sus Cuentos del Río de la Plata, tienen el ambiente de la ciudad. Salaverri tiene marcada predilección por los artistas y manifiesta culto a la mujer, cuando aparecen figuras femeninas en sùs obras. Sus tipos de mujer se caracterizan por un hondo espíritu de sacrificio y abnegación. Adolfo Montiel Ballesteros ha estado en el cuerpo diplomático y publicó su primer libro de cuentos estando en Florencia. Posee Montiel Ballesteros un conocimiento profundo y amargo de la vida de los peones del Uruguay. Sus observaciones son justas, su lenguaje adecuado, noble su finalidad. Entre sus muchos libros de cuentos se pueden mencionar: Cuentos uruguayos, Fábulas y cuentos populares, Alma nuestra, Los rostros pálidos, Luz mala, y otros. Otto Miguel Cione, que acierta lo mismo en el cuento exótico que en el rural o en el citadino, nació en el Paraguay pero ha vivido toda su vida intelectual en Uruguay. Cultivó el drama y la novela, pero ha adquirido nombre también como 
cuentista. Obras importantes son Caraguatá, Chola se casa, La eterna esfinge. Manuel Medina Betancour se dió o conocer como cuentista con Cuentos al corazón. Después publicó otros libros de cuentos: Almas y pasiones, Cuentos de otoño, Todos, Cuentos de la ciudad de Montevideo, y otros. No escribió cuentos campesinos, como lo hicieron otros. José Pedro Bellán, es un "self-made man" que está interesado mayormente en el teatro, pero que ha escrito varios libros de cuentos, como Huerco, Doñarramano, Los amores de Juan Rivault, El pecado de Alejandra Leonard.

Entre los más jóvenes y prometedores cuentistas del Uruguay actual pueden citarse a Francisco Espínola, que escribe sobre las miserias del gaucho, la pampa ardiente con todas sus pasiones y sus conflictos. También cultiva el drama y la novela, además del cuento. Emplea como ingrediente fundamental del cuento el colorido, el carácter, lo patético, la lengua rotunda y vernácula. Raza ciega, libro de cuentos, le valió un renombre inmediato. Antonio Soto (Boy), nació en España pero está identificado con la literatura uruguaya. Se especializa en cuentos para niños, como en Las parejas negras, La casa de los pájaros. Serafín J. García, criado en el interior del país, se ha dedicado preferentemente al cuento de ambiente campero, que ha publicado en revistas de Montevideo y Buenos Aires. Es profundo conocedor del campo del Uruguay, de sus paisajes y de sus hombres. Posee un estilo sobrio y brillante que maneja con real maestria. Deben mencionarse En carne viva, Tierra amarga, Babujas y Barro y sol. Víctor M. Dotti, uno de los más jóvenes cuentistas del gaucho. Ha coleccionado siete cuentos en Los alambradores, que tratan sobre el gaucho y sus trabajos en los campos. Esta obra obtuvo gran éxito y colocó a su autor, desde el primer instante, entre los primeros cultivadores del cuento uruguayo. Para finalizar el cuento en el Uruguay merecen citarse también a Enrique Amorim, que también escribe cuentos policíacos, a Santiago Dossetti, Luis Giordiano, Alberto Lasplaces, Juan María Magallanes y otros muchos.

José SÁnchez, Universidad de Illinois, Chicago. 